\section{Pharyngeale Obstruktion}

Helga Peter

Marburg, Deutschland

\section{Definition}

Funktioneller Verschluss im Rachenbereich, der nachts begünstigt wird durch Fetteinlagerungen im Halsbereich, Glossoptose,

Tonusverlust der Schlundmuskulatur oder Adipositas. Auch ein
Zusammenhang mit nächtlichen Wassereinlagerungen im Halsbereich (fluid shift) wird diskutiert.

Siehe auch

- „Schnarchen“

- „Schlafbezogene Atmungsstörungen“

- „Obstruktive Schlafapnoe“

- „,Gestörter Schlaf, seine Muster in der Kardiorespiratorischen Polysomnographie“"

- „Zerebrale Ischämie“

- „Mechanische Ventilation“ 